\title{
Glicerina bruta em suplementos para bovinos de corte a pasto no período seco
}

\author{
Leonardo Antônio Botini(1), Kamila Andreatta Kling de Moraes( ${ }^{(1)}$, Eduardo Henrique Bevitori Kling de Moraes ${ }^{(1)}$, \\ Douglas dos Santos Pina(1), Diego Cordeiro de Paula ${ }^{(1)}$, Alvair Hoffmann ${ }^{(1)}$, Helio Stinguel ${ }^{(1)}$, \\ Leandro Munhoz Socreppa ${ }^{(1)}$ e Daniel Mendonça de Meneses ${ }^{(1)}$
}

\begin{abstract}
(1)Universidade Federal de Mato Grosso, Campus Universitário de Sinop, Avenida Alexandre Ferronato, № 1.200, CEP 78557-267 Sinop, MT, Brasil. E-mail: botinizoo@hotmail.com, kamila@ufmt.br, edukling@ufmt.br, douglaspina@ufmt.br, diegodepaula94@hotmail.com, alvairtnn@hotmail.com, heliostinguel@gmail.com, leandroms@zootecnista.com.br, danielmeneseszoo@hotmail.com
\end{abstract}

Resumo - O objetivo deste trabalho foi avaliar o efeito da substituição do milho pela glicerina bruta (GB) sobre os parâmetros nutricionais e o desempenho de bovinos de corte em pastagem de Urochloa brizantha 'Marandu', no período seco. Para a avaliação dos parâmetros ruminais, foram utilizados cinco bovinos da raça Nelore não fistulados, com peso corporal (PC) inicial de 331,7 $\pm 29,6 \mathrm{~kg}$, distribuídos em delineamento em quadrado latino 5x5. Para a avaliação do desempenho, foram utilizados 30 bovinos, com PC médio de $312,4 \pm 23,3 \mathrm{~kg}$, distribuídos em delineamento inteiramente casualizado. Avaliaram-se suplementos concentrados $(20 \%$ de proteína bruta) com 0, 33, 66 e 100\% de GB em substituição ao milho, fornecidos na quantidade de $4,0 \mathrm{~kg}$ por animal por dia. Os consumos de matéria seca (MS) de suplemento, total e de pasto, bem como o de matéria orgânica (MO) digestível, apresentaram comportamento quadrático frente aos níveis de substituição. As digestibilidades aparentes de MS, MO, fibra em detergente neutro e MO digerida, bem como o ganho médio diário, também apresentaram comportamento quadrático. Em suplementos concentrados fornecidos na quantidade de $10 \mathrm{~g} \mathrm{~kg}^{-1}$ de peso corporal, a substituição total do milho pela glicerina bruta reduz o consumo de suplemento e de matéria orgânica digerida, além do desempenho de bovinos de corte em pastejo.

Termos para indexação: biodiesel, glicerol, suplementação.

\section{Crude glycerin in supplements for beef cattle at pasture during the dry season}

Abstract - The objective of this work was to evaluate the effect of the replacement of corn by crude glycerin (CG) on the nutritional parameters and performance of beef cattle grazing Urochloa brizantha 'Marandu' during the dry season. To evaluate ruminal parameters, five non-fistulated Nelore steers were used, with average initial body weight (BW) of $331.7 \pm 29.6 \mathrm{~kg}$, allotted to a $5 \times 5$ Latin square. To evaluate performance, 30 steers were used, with average BW of $312.4 \pm 23.3 \mathrm{~kg}$, allotted to a completely randomized design. Concentrated supplements (20\% crude protein) with $0,33,66$, and $100 \%$ CG replacing corn were evaluated and provided in the amount of $4.0 \mathrm{~kg}$ per animal per day. Intake of supplement, total, and pasture dry matter (DM), as well as of digestible organic matter (OM), presented quadratic behavior to the replacement levels. The apparent digestibility of DM, OM, neutral detergent fiber, and digestible OM, as well as average daily gain, also showed quadratic behavior. In concentrated supplements provided in the amount of $10 \mathrm{~g} \mathrm{~kg}^{-1}$ body weight, the total replacement of corn by crude glycerin reduces supplement and digestible organic matter intake, besides the performance of grazing beef cattle.

Index terms: biodiesel, glycerol, supplements.

\section{Introdução}

Com a crescente produção de biodiesel no Brasil, aumenta, também, a produção de glicerina bruta (GB), coproduto dessa indústria. Os ruminantes têm a capacidade de utilizar o glicerol presente na GB como precursor gliconeogênico (Chung et al., 2007), para a manutenção dos níveis plasmáticos de glicose. Assim, a GB pode ser incluída em dietas como um ingrediente energético alternativo ao milho.

No entanto, a maioria dos trabalhos disponíveis na literatura foi realizada in vitro, com bovinos leiteiros ou em animais em regime de confinamento. Leão et al. (2012) recomendam a inclusão de até $24 \%$ de GB em substituição ao milho, na matéria seca(MS) da dieta total de bovinos em confinamento. Já Peripolli et al. (2014), 
em estudo in vitro, observaram que a substituição do milho por níveis crescentes de GB na dieta não afeta a concentração de amônia ruminal, o teor de energia metabolizável, as digestibilidades in vitro da matéria orgânica (MO) e da fibra em detergente neutro (FDN), nem os parâmetros da degradação ruminal.

Apesar desses resultados, ainda há escassez de informações sobre a utilização da GB para suplementação de bovinos de corte em pastejo, principalmente quanto ao nível ideal de substituição do milho pela GB em suplementos concentrados.

O objetivo deste trabalho foi avaliar o efeito da substituição do milho pela glicerina bruta sobre os parâmetros nutricionais e o desempenho de bovinos de corte em pastagem de Urochloa brizantha 'Marandu', no período seco.

\section{Material e Métodos}

Foram realizados dois experimentos no Município

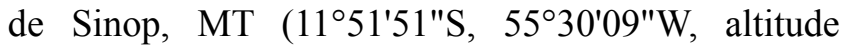
de $345 \mathrm{~m}$ ), entre junho e agosto de 2013, os meses referentes ao período seco. A área experimental foi constituída de piquetes formados com capim-marandu ( $U$. brizantha), dos quais cinco piquetes de 0,5 ha cada, foram usados para avaliação dos parâmetros nutricionais e cinco de 2,0 ha, para avaliação do desempenho.

Para a avaliação dos parâmetros nutricionais consumo, digestibilidade, parâmetros ruminais, balanço de compostos nitrogenados e eficiência microbiana -, foram utilizados cinco animais machos não castrados da raça Nelore, não fistulados, com peso corporal (PC) inicial de $331,7 \pm 29,6 \mathrm{~kg}$ e idade média de 21 meses, distribuídos em delineamento em quadrado latino $5 \times 5$. $\mathrm{O}$ experimento teve duração de 65 dias, divididos em cinco períodos experimentais com 13 dias de duração, dos quais os primeiros sete dias foram destinados à adaptação às dietas e às condições experimentais.

Para a avaliação do desempenho, foram utilizados 30 animais machos da raça Nelore, não castrados, com PC médio de $312,4 \pm 23,3 \mathrm{~kg}$ e idade média de 21 meses, distribuídos em delineamento inteiramente casualizado, tendo-se adotado o PC como covariável. A avaliação do desempenho teve duração de 84 dias, divididos em três períodos experimentais de 28 dias.

Avaliaram-se suplementos concentrados isonitrogenados (Tabelas 1 e 2) contendo diferentes níveis de
GB (0, 33, 66 e 100\%) em substituição ao milho, além da suplementação mineral (tratamento controle). Os suplementos concentrados foram ofertados diariamente às $10 \mathrm{~h}$ na quantidade de $4,0 \mathrm{~kg}$ por animal por dia, e as sobras foram pesadas diariamente. A GB estudada originou-se do processamento do grão de soja e apresentou teores de $87,6 \%$ de matéria seca (MS); $4,95 \%$ de cinzas sulfatadas; $3,35 \%$ de cloreto; $5,49 \%$ de cloreto com $\mathrm{NaCl} ; 0,01 \%$ de metanol; e $81 \%$ de glicerol.

Os animais foram pesados no início e no final do experimento após serem submetidos a jejum de sólidos por 12 horas, para reduzir possíveis diferenças quanto ao enchimento do trato digestivo.

Para minimizar a possível influência da variação na disponibilidade de MS de pasto entre os piquetes (experimento de desempenho), realizou-se o rodízio dos animais entre os piquetes a cada 15 dias, tendo-se mantido os mesmos tratamentos.

A cada 13 dias, foram efetuadas amostragens do pasto por meio de dois métodos. No primeiro método, amostras foram coletadas para quantificação da massa de MS e de MS potencialmente digestível (MSpd). Determinou-se a massa de forragem por meio do método quadrado (quadrado de $50 \times 50 \mathrm{~cm}, 0,25 \mathrm{~m}^{2} \mathrm{com}$ quatro medições por piquete), com cortes da forragem a $10 \mathrm{~cm}$ do solo. Após a coleta, foram separados os componentes: lâmina foliar, colmo verde+bainha e material senescente. A MSpd foi estimada de acordo com a equação proposta por Paulino et al. (2008): $\mathrm{MSpd}=0,98 \times(100-\mathrm{FDNcp})+(\mathrm{FDN}-\mathrm{FDNi}), \mathrm{em}$ que 0,98 é o coeficiente de digestibilidade verdadeiro do conteúdo celular; FDNcp é a fibra em detergente neutro corrigida para cinzas e proteína; FDN é a fibra em detergente neutro; e FDNi é a FDN indigestível.

No segundo método, a amostragem do pasto consumido pelos animais foi executada via simulação manual de pastejo, ao se identificar o tipo de material que o animal ingeria, para coleta de amostra semelhante. As coletas foram realizadas por um único amostrador, para evitar variações em cada amostragem.

Para a estimativa do consumo de MS do pasto (MSP), a FDNi dos alimentos e do pasto foi utilizada como indicador interno, e o óxido crômico $\left(\mathrm{Cr}_{2} \mathrm{O}_{3}\right)$, como indicador externo, para estimativa da excreção fecal. $\mathrm{O} \mathrm{Cr}_{2} \mathrm{O}_{3}$ foi acondicionado em cartuchos de papel e introduzido diretamente via sonda esofágica em dose única diária, de $15 \mathrm{~g}$ por animal, às $11 \mathrm{~h}$, do terceiro ao décimo segundo dia experimental. 
Amostras de fezes foram coletadas entre o oitavo e o décimo segundo dia do período experimental: no oitavo dia, às $8 \mathrm{~h}$; no décimo dia, às $12 \mathrm{~h}$; e no décimo segundo dia, às $16 \mathrm{~h}$. As fezes foram coletadas diretamente do reto dos animais em quantidades de $200 \mathrm{~g}$, identificadas por animal e armazenadas em freezer a $-20^{\circ} \mathrm{C}$. Foi elaborada uma amostra composta de fezes com base no peso seco ao ar, por animal, dos três dias de coleta.

O cálculo da excreção fecal foi feito com base na razão entre a quantidade do indicador fornecido e a sua concentração nas fezes: excreção fecal $(\mathrm{kg}$ por dia $)=$ [(quantidade fornecida do indicador $(\mathrm{g})) /($ concentração do indicador nas fezes $\left(\mathrm{g} \mathrm{kg}^{-1}\right.$ de MS $\left.\left.)\right)\right] \times 100$.

A FDNi das amostras foi determinada após 264 horas de incubação ruminal (Casali et al., 2008). As amostras de pasto, concentrados e fezes foram analisadas quanto às concentrações de MS, MO, proteína bruta (PB) e extrato etéreo (EE), de acordo com Horwitz \& Latimer Junior (2005). A FDN foi determinada pelos métodos descritos por Van Soest \& Robertson (1985) e Mertens (2002).

As análises de FDN foram realizadas em sistema Ankon, tendo-se utilizado sacos de TNT, com dimensões de $5 \times 5 \mathrm{~cm}$, e mantido relações médias de $14 \mathrm{mg} \mathrm{cm}^{-2}$ de MS de tecido e $100 \mathrm{~mL}$ de detergente neutro por grama de amostra seca ao ar. Os teores de carboidratos não fibrosos foram calculados conforme Hall (2000).

As estimativas do consumo voluntário de matéria seca (CMS) foram obtidas ao se utilizar, como indicador interno, a $\mathrm{FDNi}$, por meio da seguinte equação: $\mathrm{CMS}=\{[(\mathrm{EFxCIF})-\mathrm{IS}] / \mathrm{CIFO}\}+\mathrm{CMSS}$, em que EF é a excreção fecal (kg por dia); CIF é a concentração do indicador nas fezes $\left(\mathrm{kg} \mathrm{kg}^{-1}\right)$; IS é o indicador presente no suplemento ( $\mathrm{kg}$ por dia); CIFO é a concentração do indicador na forragem $\left(\mathrm{kg} \mathrm{kg}^{-1}\right)$; e CMSS é o consumo de matéria seca de suplemento (kg por dia).

Tabela 1. Composição dos suplementos.

\begin{tabular}{lccccc}
\hline Ingrediente & Mineral & \multicolumn{4}{c}{ Nível de substituição (\%) } \\
\cline { 3 - 6 } & & 0 & 33 & 66 & 100 \\
\hline Mineral 80P(1) & 2,50 & 2,50 & 2,50 & 2,50 & 2,50 \\
Ureia & 2,50 & 2,50 & 2,50 & 2,50 & 2,50 \\
Farelo de soja & - & 14,00 & 19,40 & 24,75 & 31,0 \\
Milho & - & 81,00 & 54,00 & 27,00 & 0,00 \\
Glicerina bruta & - & 0,00 & 21,60 & 43,25 & 64,00 \\
\hline
\end{tabular}

(1) $130 \mathrm{~g}$ de Ca; $80 \mathrm{~g}$ de P; $20 \mathrm{~g}$ de $\mathrm{Mg} ; 20 \mathrm{~g}$ de $\mathrm{S} ; 135 \mathrm{~g}$ de Na; $114 \mathrm{mg}$ de $\mathrm{Cu} ; 1.072 \mathrm{mg}$ de $\mathrm{Mn} ; 4.146 \mathrm{mg}$ de Zn; $121 \mathrm{mg}$ de I; $89 \mathrm{mg}$ de Co; $21 \mathrm{mg}$ de Se; e P em solução de ácido cítrico (mínimo) a 90\%.
Para relacionar o consumo ao $\mathrm{PC}$ dos animais, utilizou-se, como referência, o peso médio, estimado pelos valores inicial e final de cada período.

Amostras de sangue, urina e líquido ruminal foram coletadas no décimo terceiro dia, aproximadamente 4 horas após o fornecimento do suplemento. As amostras de sangue foram coletadas por punção da artéria caudal, tendo-se utilizado kits comerciais a vácuo, com gel acelerador da coagulação. Logo após as coletas, as amostras foram centrifugadas a $4.000 \mathrm{rpm}$, durante $15 \mathrm{~min}$, e o soro foi congelado.

As amostras de urina $(10 \mathrm{~mL})$ foram coletadas na forma de spot em micção espontânea. Após a coleta, as amostras foram diluídas em $40 \mathrm{~mL}$ de $\mathrm{H}_{2} \mathrm{SO}_{4}(0,036) \mathrm{N}$ e congeladas para posterior determinação dos teores de ureia, creatinina e derivados de purina.

$\mathrm{O}$ cálculo do volume urinário diário foi obtido pela relação entre a excreção diária de creatinina (EC), proposta por Barbosa et al. (2006), e a sua concentração nas amostras spot: $\mathrm{EC}\left(\mathrm{mg} \mathrm{kg}^{-1} \mathrm{de} \mathrm{PV}\right)=27,11 \mathrm{PC}$, em que PV é o peso vivo. Dessa forma, a excreção urinária diária de compostos nitrogenados foi determinada pelo produto entre a sua concentração nas amostras spot e o valor estimado de volume urinário.

As análises de alantoína na urina foram realizadas pelo método colorimétrico, seguindo Fujihara et al. (1987). A excreção total de derivados de purinas foi calculada pela soma das quantidades de alantoína e ácido úrico excretadas na urina, expressas em $\mathrm{mmol}$ por dia. As purinas absorvidas (Y, mmol por dia) foram calculadas a partir da excreção de derivados de purinas (X, mmol por dia) por intermédio da equação:

Tabela 2. Composição bromatológica dos suplementos e do pasto.

\begin{tabular}{lccccc}
\hline Item & \multicolumn{4}{c}{ Níveis de substituição (\%) } & Pasto \\
\cline { 2 - 5 } & 0 & 33 & 66 & 100 & \\
\hline Matéria seca (\%) $^{\text {Matéria orgânica }}{ }^{(1)}$ & 90,03 & 89,6 & 89,2 & 88,8 & 53,8 \\
Proteína bruta $^{(1)}$ & 91,48 & 90,2 & 89,0 & 87,8 & 94,1 \\
N insolúvel em DN $^{(2)}$ & 20,08 & 20,3 & 20,4 & 21,0 & 4,2 \\
Extrato etéreo $^{(1)}$ & 15,23 & 16,0 & 16,5 & 17,0 & 50,2 \\
Carboidratos não fibrosos $^{(1)}$ & 2,91 & 4,8 & 6,6 & 8,3 & 0,9 \\
FDN $^{(1)}$ & 55,1 & 56,6 & 58,1 & 59,1 & 16,2 \\
FDN corrigida para proteína $^{(1)}$ & 17,8 & 13,3 & 8,7 & 4,2 & 72,0 \\
FDN indigestível $^{(1)}$ & 12,4 & 8,3 & 4,3 & 0,3 & 65,1 \\
\hline
\end{tabular}

(1)Percentagem de matéria seca. (2)Percentagem do nitrogênio total. DN, detergente neutro. FDN, fibra em detergente neutro. 
$\mathrm{Y}=\left(\mathrm{X}-0,301 \mathrm{PV}^{0,75}\right) / 0,80$, em que 0,80 é igual à recuperação de purinas absorvidas como derivados de purinas; e 0,301PV $\mathrm{PV}^{0,75}$ é a contribuição endógena para a excreção de purinas (Barbosa et al., 2011).

A síntese ruminal de compostos nitrogenados (Y, $\mathrm{g}$ de $\mathrm{N}$ microbiano por dia) foi calculada em função das purinas absorvidas ( $\mathrm{X}, \mathrm{mmol}$ por dia), tendo-se utilizado a equação descrita por Chen \& Gomes (1992): $\mathrm{Y}=70 \mathrm{X} / 0,93 \times 0,137 \times 1.000$, em que 70 é $\mathrm{o}$ conteúdo de $\mathrm{N}$ nas purinas ( $\mathrm{mg} \mathrm{mmol}{ }^{-1}$ de $\left.\mathrm{N}\right), 0,93$ é a digestibilidade verdadeira das purinas; e 0,137 é a relação $\mathrm{N}$ nas purinas:média de $\mathrm{N}$ total nas bactérias isoladas no rúmen (Barbosa et al., 2011). A eficiência microbiana foi expressa por meio da unidade: grama de $\mathrm{PB}$ microbiana por quilograma de MO digerida (MOD).

As amostras de líquido ruminal foram coletadas para estimar o $\mathrm{pH}$ e a concentração de amônia. As análises de $\mathrm{pH}$ foram realizadas imediatamente após a coleta por peagâmetro digital. Para a determinação de amônia, foram separadas alíquotas de $50 \mathrm{~mL}$, fixadas com $1,0 \mathrm{~mL}$ de $\mathrm{H}_{2} \mathrm{SO}_{4}(1: 1)$, que foram acondicionadas em recipientes de plástico, identificadas e congeladas a $-20^{\circ} \mathrm{C}$.

As comparações entre médias de tratamentos foram realizadas por intermédio de contrastes ortogonais: suplementação mineral x suplementação concentrada e efeitos de ordem linear, quadrática e cúbica da inclusão de GB. Para todos os procedimentos estatísticos, adotou-se $\alpha=0,10$ como limite máximo tolerável para o erro tipo I. Quando ambos os modelos (linear e quadrático) foram significativos, optou-se pelo modelo que representasse o polinômio de maior grau.

\section{Resultados e Discussão}

As médias de massa de forragem observadas durante o experimento foram de 7,8, 5,0, 2,7 e $0,7 \mathrm{Mg} \mathrm{ha}^{-1}$, respectivamente, para massa seca total (MST), MSpd, MS de colmo e MS de folha (Figura 1). Paulino et al. (2008), ao associar a produção por animal e por área, sugeriram o fornecimento entre 4 e $5 \%$ do PC em MSpd de pasto, para otimizar o desempenho animal. A massa média de MSpd durante o experimento foi de $5,8 \%$ do PC, próxima do valor preconizado pelos autores, o que mostra que a quantidade ofertada não foi obstáculo para a capacidade seletiva dos animais.

O teor de PB do pasto foi em média 4,22\% (Tabela 2), abaixo do valor mínimo de $10 \%$, considerado por
Sampaio et al. (2010) como nível que otimiza a utilização de substratos energéticos da forragem e favorece condições para que os microrganismos ruminais apresentem plena capacidade de degradação dos substratos fibrosos da forragem basal. Entretanto, verificou-se que o fornecimento de suplementos concentrados propiciou maior consumo de MST e MSP do que apenas o suplemento mineral (Tabela 3).

Quanto aos níveis de GB, constatou-se que os consumos de MST, MSP e de nutrientes apresentaram comportamento quadrático. Esse comportamento pode ser atribuído ao menor consumo de MS de suplemento quando houve a substituição total do milho pela GB. Essa redução no consumo do suplemento pode ser explicada, em parte, pelo alto teor de sódio na GB. Segundo o National Research Council (2000), para animais com $300 \mathrm{~kg}$ de PC e taxa de ganho de $1,0 \mathrm{~kg}$ por dia, a exigência dietética de sódio estaria entre $6,0 \mathrm{e}$ $10 \mathrm{~g}$ por dia. Contudo, para animais a pasto, o programa BR-Corte (Valadares Filho et al., 2010) indica o valor de 3,51 g por dia. Com a substituição total do milho pela $\mathrm{GB}$, o teor de sódio no suplemento apresentou 88,5 g de sódio, valor acima do requerimento nutricional. Além disso, Carter \& Grovum (1990) apontam que sais de elevada capacidade iônica, como o cloreto de sódio, contribuem efetivamente para a ampliação na molalidade (ou molaridade) do meio ruminal, o que mostra estreita relação negativa com o consumo; isso pode ter levado ao menor consumo de suplemento pelos animais quando houve a substituição total do milho pela GB.

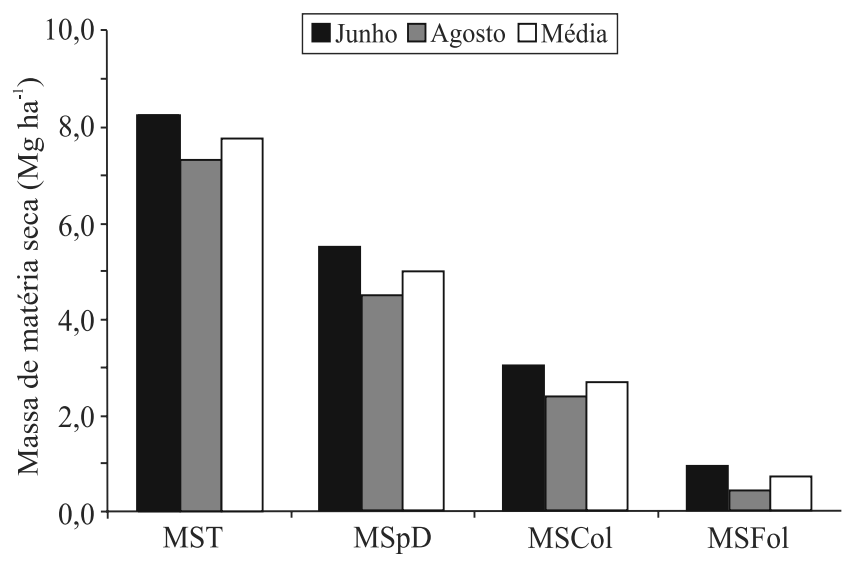

Figura 1. Massas de matéria seca total (MST), matéria seca potencialmente digestível $(\mathrm{MSpD})$, matéria seca de colmo (MSCol) e matéria seca de folha (MSFol). 
O menor consumo de MST e MSP (Tabela 3) pode ser consequência de mecanismos de inibição do crescimento e de atividade das bactérias celulolíticas, causados por altos níveis de inclusão de GB na dieta. De acordo com Abughazaleh et al. (2010), a inclusão de glicerina pura (99,5\%) em 7,2 e 10,8\% na MS das dietas deprimiu a digestibilidade da FDN e as concentrações de DNA de Butyrivibrio fibrisolvens, Selenomonas ruminantium e Clostridium proteoclasticum. Esse efeito também foi evidenciado por Abo El-Nor et al. (2010), que observaram redução na digestibilidade da FDN e na concentração do DNA das bactérias $B$. fibrisolvens e $S$. ruminantium, ao adicionar glicerina na dieta em concentrações superiores a $72 \mathrm{~g}$ de glicerol por $\mathrm{kg}$ de MS. Conforme estes autores, o glicerol pode ter afetado a adesão às partículas de alimentos, o que reduz a disponibilidade de nutrientes para essas bactérias.

Paggi et al. (2004), com base em estudos in vitro, relataram que a atividade celulolítica do rúmen foi reduzida quando a concentração de glicerol passou de 50 para $300 \mathrm{mmol} \mathrm{L}^{-1}$. Esses autores observaram diminuição nas digestibilidades da matéria orgânica e da fibra em detergente neutro. Parsons et al. (2009), ao avaliar o efeito da inclusão de diferentes níveis de glicerina na dieta de novilhas de corte confinadas, constataram reduções no consumo de MS com a inclusão de GB acima de $8 \%$ na dieta. Pyatt et al. (2007), ao analisar dietas contendo $10 \%$ de GB, também verificaram redução no consumo de MS. No presente trabalho, os níveis de GB da dieta foram de $8,70,16,87$ e $33,81 \%$ para os níveis de 33,66 e $100 \%$, respectivamente.

As médias para as digestibilidades aparentes da MS, MO, PB, FDN e para o teor de MOD apresentaram comportamento quadrático (Tabela 4), com queda nos coeficientes com a substituição total do milho pela GB. As menores digestibilidades encontradas podem ser decorrentes da inibição do crescimento e da atividade das bactérias celulolíticas (Paggi et al., 2004; Abo El-Nor et al., 2010; Abughazaleh et al., 2010).

$\mathrm{O}$ pH ruminal, parâmetro indicativo da fermentação ruminal, não foi afetado pela inclusão de GB na dieta (Tabela 5). O pH ruminal pode variar de 5,5 a 7,2, com valores baixos detectados em intervalos de tempo curtos, após alimentação dos animais com dietas ricas em concentrado, sendo que valores de $\mathrm{pH}$ abaixo de 6,0 podem inibir as bactérias fermentadoras de celulose e diminuir a eficiência da síntese de proteína microbiana (Valadares Filho \& Pina, 2006). No presente trabalho, os valores de $\mathrm{pH}$ ruminal estiveram acima do valor que poderia inibir o crescimento das bactérias celulolíticas.

Tabela 3. Médias de quadrados mínimos para os consumos de matéria seca de suplemento (MSS), total (MST) e de pasto (MSP), bem como para o consumo de matéria orgânica (MO), proteína bruta (PB), extrato etéreo (EE), fibra em detergente neutro (FDN), carboidratos não fibrosos (CNF) e MO digerida (MOD) por bovinos de corte, em função dos suplementos.

\begin{tabular}{|c|c|c|c|c|c|c|c|c|c|}
\hline \multirow[t]{2}{*}{ Item } & \multirow[t]{2}{*}{ Mineral } & \multicolumn{4}{|c|}{ Níveis de substituição (\%) } & \multirow{2}{*}{$\begin{array}{l}\text { CV } \\
(\%)\end{array}$} & \multicolumn{3}{|c|}{ Contrastes } \\
\hline & & 0 & 33 & 66 & 100 & & $\mathrm{CON}^{(1)}$ & $\mathrm{L}^{(2)}$ & $\mathrm{Q}^{(3)}$ \\
\hline \multicolumn{10}{|c|}{$\mathrm{kg}$ por dia } \\
\hline MSS & 0,01 & 3,60 & 3,58 & 3,51 & 2,26 & 17,51 & $<0,0001$ & 0,0567 & 0,0653 \\
\hline MST & 5,11 & 9,77 & 9,93 & 10,25 & 7,57 & 12,92 & $<0,0001$ & 0,0563 & 0,0754 \\
\hline MSP & 5,11 & 6,17 & 6,35 & 6,75 & 5,31 & 18,00 & $<0,0001$ & 0,0644 & 0,0853 \\
\hline MO & 4,80 & 9,21 & 9,22 & 9,23 & 6,99 & 9,11 & $<0,0001$ & 0,0456 & 0,0567 \\
\hline PB & 0,22 & 0,98 & 0,99 & 1,00 & 0,70 & 10,43 & $<0,0001$ & 0,0434 & 0,0675 \\
\hline EE & 0,04 & 0,15 & 0,22 & 0,28 & 0,23 & 9,39 & $<0,0001$ & 0,0501 & 0,0704 \\
\hline FDN & 3,72 & 5,00 & 5,06 & 5,08 & 4,05 & 11,56 & $<0,0001$ & 0,0498 & 0,0599 \\
\hline $\mathrm{CNF}$ & 0,83 & 3,00 & 3,08 & 3,14 & 2,22 & 11,23 & $<0,0001$ & 0,0403 & 0,0565 \\
\hline MOD & 2,33 & 5,37 & 6,05 & 6,25 & 4,61 & 17,01 & 0,0324 & 0,0503 & 0,0689 \\
\hline \multicolumn{10}{|c|}{$\mathrm{g} \mathrm{kg}^{-1}$ de peso corporal } \\
\hline MST & 14,6 & 28,5 & 28,6 & 28,6 & 22,1 & 16,54 & 0,0456 & 0,0563 & 0,0675 \\
\hline MSP & 14,6 & 17,9 & 18,0 & 18,0 & 15,5 & 13,20 & 0,0201 & 0,0456 & 0,0597 \\
\hline MOD & 13,7 & 16,9 & 17,1 & 18,4 & 14,6 & 15,69 & 0,0342 & 0,0512 & 0,0671 \\
\hline FDN & 10,6 & 14,5 & 14,5 & 15,1 & 11,6 & 13,44 & 0,0345 & 0,0451 & 0,0532 \\
\hline
\end{tabular}

${ }^{(1)}$ Suplementação mineral versus suplementação concentrada. ${ }^{(2)}$ Efeito de ordem linear do nível de glicerina bruta. ${ }^{(3)}$ Efeito de ordem quadrática do nível de glicerina bruta. 
A concentração de $\mathrm{NH}_{3}$ ruminal foi superior para os animais que receberam suplementação concentrada, em comparação aos que receberam apenas suplemento mineral. Não houve efeito da substituição do milho pela GB quanto à concentração de $\mathrm{NH}_{3}$. Peripolli et al. (2014) avaliaram a substituição do milho por níveis crescentes de GB na dieta e também observaram ausência de efeitos sobre a concentração de $\mathrm{NH}_{3}$ ruminal.

Detmann et al. (2009) afirmam que são necessários $15 \mathrm{mg}$ de $\mathrm{NH}_{3}$ por dL de fluido ruminal para maximizar a produção microbiana em bovinos alimentados com forragem de baixa qualidade. Portanto, pode-se inferir que a menor digestibilidade da matéria seca, quando os animais receberam 100\% de glicerina bruta, não pode ser atribuída à limitação de concentrações adequadas de $\mathrm{NH}_{3}$ ruminal. Segundo Paggi et al. (2004), Abo El-Nor et al. (2010) e Abughazaleh et al. (2010), esse efeito pode estar mais relacionada a mecanismos de inibição do crescimento e à atividade das bactérias celulolíticas.

$\mathrm{O}$ balanço de compostos nitrogenados (BN) apresentou comportamento quadrático em função do aumento da GB nos suplementos (Tabela 5) e foi positivo mesmo nos animais que receberam apenas suplemento mineral. Isso mostra que houve retenção de proteína no organismo, o que proporcionou condições para que não ocorresse perda de peso nos animais, $o$ que indica que as exigências de proteína nas dietas estiveram acima da mantença.

A velocidade de crescimento também é consequência da maior quantidade de energia ingerida; assim, o comportamento observado para consumo de energia (MOD), juntamente com o $\mathrm{BN}$, refletiu-se no desempenho dos animais, cujo comportamento foi quadrático em função do aumento do nível de GB nos suplementos (Tabela 6).

Tabela 4. Médias de quadrados mínimos para as digestibilidades aparentes (\%) de matéria seca (MS), matéria orgânica (MO), fibra em detergente neutro (FDN) e MO digerida (MOD) em bovinos de corte, em função dos suplementos.

\begin{tabular}{|c|c|c|c|c|c|c|c|c|c|}
\hline \multirow[t]{2}{*}{ Variável } & \multirow[t]{2}{*}{ Mineral } & \multicolumn{4}{|c|}{ Níveis de substituição (\%) } & \multirow{2}{*}{$\begin{array}{l}\text { CV } \\
(\%)\end{array}$} & \multicolumn{3}{|c|}{ Contrastes } \\
\hline & & 0 & 33 & 66 & 100 & & $\mathrm{CON}^{(1)}$ & $\mathrm{L}^{(2)}$ & $\mathrm{Q}^{(3)}$ \\
\hline MS & 49,12 & 63,42 & 64,65 & 64,05 & 57,05 & 14,59 & 0,0213 & 0,0384 & 0,0699 \\
\hline MO & 46,01 & 55,14 & 56,21 & 56,89 & 52,02 & 13,56 & 0,0216 & 0,0549 & 0,0796 \\
\hline Proteína bruta & 52,22 & 62,21 & 62,32 & 62,55 & 51,61 & 17,02 & 0,0398 & 0,0604 & 0,0743 \\
\hline FDN & 44,99 & 64,31 & 65,49 & 65,59 & 55,48 & 12,89 & 0,0511 & 0,0761 & 0,0701 \\
\hline \multicolumn{10}{|c|}{$\mathrm{g} \mathrm{kg}^{-1}$ de matéria seca } \\
\hline MOD & 428,37 & 510,05 & 520,33 & 528,01 & 478,75 & 14,46 & 0,0532 & 0,0754 & 0,0800 \\
\hline
\end{tabular}

${ }^{(1)}$ Suplementação mineral versus suplementação concentrada. ${ }^{(2)}$ Efeito de ordem linear do nível de glicerina bruta. ${ }^{(3)}$ Efeito de ordem quadrática do nível de glicerina bruta.

Tabela 5. Médias de quadrados mínimos para $\mathrm{pH}$ ruminal, concentração de nitrogênio amoniacal ruminal $\left(\mathrm{NH}_{3}\right)$ e de nitrogênio ureico no soro (NUS), consumo de nitrogênio $(\mathrm{CN})$, excreção fecal de nitrogênio (EFN), excreção urinária de nitrogênio (EUN), balanço nitrogenado aparente (BN) e eficiência de síntese de proteína microbiana (EFM) em bovinos de corte, em função dos suplementos.

\begin{tabular}{|c|c|c|c|c|c|c|c|c|c|}
\hline \multirow[t]{2}{*}{ Item $^{(1)}$} & \multirow[t]{2}{*}{ Mineral } & \multicolumn{4}{|c|}{ Níveis de substituição (\%) } & \multirow{2}{*}{$\begin{array}{l}\text { CV } \\
(\%)\end{array}$} & \multicolumn{3}{|c|}{ Contrastes } \\
\hline & & 0 & 33 & 66 & 100 & & $\mathrm{CON}^{(2)}$ & $\mathrm{L}^{(3)}$ & $\mathrm{Q}^{(4)}$ \\
\hline$\overline{\mathrm{pH}}$ & 7,04 & 6,82 & 6,86 & 7,07 & 7,19 & 18,31 & 0,1823 & 0,2122 & 0,3012 \\
\hline $\mathrm{NH}_{3}$ & 7,77 & 14,18 & 14,89 & 15,62 & 15,62 & 15,65 & $<0,0001$ & 0,1553 & 0,1710 \\
\hline NUS & 13,84 & 22,08 & 20,65 & 20,46 & 17,83 & 17,23 & $<0,0001$ & 0,0441 & 0,0589 \\
\hline $\mathrm{CN}$ & 35,88 & 157,40 & 159,12 & 159,26 & 111,81 & 16,91 & $<0,0001$ & 0,0434 & 0,0675 \\
\hline EFN & 16,39 & 44,69 & 43,84 & 43,88 & 43,43 & 18,18 & $<0,0001$ & 0,1341 & 0,1564 \\
\hline EUN & 9,46 & 75,89 & 77,29 & 77,43 & 38,81 & 12,54 & 0,0048 & 0,0253 & 0,0534 \\
\hline $\mathrm{BN}$ & 10,03 & 36,82 & 37,99 & 37,95 & 29,57 & 18,32 & $<0,0001$ & 0,0498 & 0,0611 \\
\hline EFM & 96,88 & 100,23 & 101,99 & 103,35 & 102,15 & 21,59 & 0,1259 & 0,1912 & 0,1986 \\
\hline
\end{tabular}

${ }^{(1)} \mathrm{HN}_{3}$ e NUS, em mg dL ${ }^{-1} ; \mathrm{CN}$, EFN, EUN e BN, em grama por dia; e EFM, em quilograma de proteína bruta microbiana por quilograma de matéria orgânica digerida. ${ }^{(2)}$ Suplementação mineral versus suplementação concentrada. ${ }^{(3)}$ Efeito de ordem linear do nível de glicerina bruta. ${ }^{(4)}$ Efeito de ordem quadrática do nível de glicerina bruta. 
Tabela 6. Peso corporal final (PCF), ganho de peso total (GPT) e ganho médio diário (GMD) de bovinos de corte em função dos suplementos.

\begin{tabular}{|c|c|c|c|c|c|c|c|c|c|}
\hline \multirow[t]{2}{*}{ Item $^{(1)}$} & \multirow[t]{2}{*}{ Mineral } & \multicolumn{4}{|c|}{ Níveis de substituição (\%) } & \multirow{2}{*}{$\begin{array}{l}\text { CV } \\
(\%)\end{array}$} & \multicolumn{3}{|c|}{ Contrastes } \\
\hline & & 0 & 33 & 66 & 100 & & $\mathrm{CON}^{(2)}$ & $\mathrm{L}^{(3)}$ & $\mathrm{Q}^{(4)}$ \\
\hline PCF (kg) & 344,17 & 393,65 & 404,53 & 398,21 & 371,88 & 4,83 & $<0,0001$ & 0,0189 & 0,0886 \\
\hline GPT (kg) & 33,47 & 82,88 & 93,67 & 75,44 & 58,32 & 27,74 & $<0,0001$ & 0,0189 & 0,0886 \\
\hline GMD (kg por animal) & 0,39 & 0,98 & 1,11 & 0,91 & 0,68 & 27,76 & $<0,0001$ & 0,0190 & 0,0798 \\
\hline
\end{tabular}

${ }^{(1)}$ Médias ajustadas por covariável. ${ }^{(2)}$ Suplementação mineral versus suplementação concentrada. ${ }^{(3)}$ Efeito de ordem linear do nível de glicerina bruta. ${ }^{(4)}$ Efeito de ordem quadrática do nível de glicerina bruta.

De acordo com Elam et al. (2008), a inclusão de 7,5 e $15 \%$ de GB na MS, para novilhas em confinamento, reduz o desempenho animal, e esse menor ganho de peso pode ser explicado pela redução na ingestão de MS e pela mudança no comportamento alimentar das novilhas.

Farias et al. (2012) concluíram que a inclusão da GB na dieta de novilhas em crescimento e suplementadas a pasto teve influência negativa no desempenho animal. Sabe-se que o uso de GB em substituição às fontes de energia na dieta de ruminantes depende da qualidade do produto. No entanto, conforme os autores a glicerina avaliada apresentava-se escura, pouco adocicada e adstringente ao paladar; características que podem ser atribuídas à presença de sais, impurezas e reagentes usados no processo de transesterificação.

Observou-se que os animais que receberam suplementos contendo $100 \%$ de GB em substituição ao milho apresentaram menores consumos de MS, tanto de pasto quanto de suplemento (Tabela 3). Consequentemente, houve menor consumo de energia (MOD) (Tabela 3) e menor BN (Tabela 5), que refletiram no menor desempenho produtivo dos animais (Tabela 6).

\section{Conclusão}

Em suplementos concentrados fornecidos na quantidade de $10 \mathrm{~g} \mathrm{~kg}^{-1}$ de peso corporal, a substituição total do milho pela glicerina bruta reduz o consumo de suplemento e de matéria orgânica digerida e o desempenho de bovinos de corte em pastejo.

\section{Agradecimentos}

À Fundação de Amparo à Pesquisa do Estado de Mato Grosso (Fapemat), pela concessão de bolsa e apoio financeiro; e à Bunge Alimentos, pela doação de glicerina bruta.

\section{Referências}

ABO EL-NOR, S.; ABUGHAZALEH, A.A.; POTU, R.B.; HASTINGSA, D.; KHATTAB, M.S.A. Effects of differing levels of glycerol on rumen fermentation and bacteria. Animal Feed Science and Technology, v.162, p.99-105, 2010. DOI: 10.1016/j. anifeedsci.2010.09.012

ABUGHAZALEH, A.A.; ABO EL-NOR, S.; IBRAHIM, S.A. The effect of replacing corn with glycerol on ruminal bacteria in continuous culture fermenters. Journal of Animal Physiology and Animal Nutrition, v.95, p.313-319, 2010. DOI: 10.1111/j.1439-0 396.2010.01056.x

BARBOSA, A.M.; VALADARES, R.F.D.; VALADARES FILHO, S. de C.; PINA, D.S.; DETMANN, E.; LEÃO, M.I. Endogenous fraction and urinary recovery of purine derivatives obtained by different methods in Nellore cattle. Journal of Animal Science, v.89, p.510-519, 2011. DOI: 10.2527/jas.2009-2366.

BARBOSA, A.M.; VALADARES, R.F.D.; VALADARES FILHO, S. de C.; VÉRAS, R.M.L.; LEÃO, M.I.; DETMANN, E.; PAULINO, M.F.; MARCONDES, M.I.; SOUZA, M.A. de. Effect of urinary collection days, concentrate levels and protein sources on creatinine, urea and purine derivatives excretions and microbial protein synthesis in Nellore cattle. Revista Brasileira de Zootecnia, v.35, p.870-877, 2006. DOI: 10.1590/S1516-35982006000300033.

CARTER, R.R.; GROVUM, W.L. Factors affecting the voluntary intake of food by sheep. 5 . The inhibitory effect of hypertonicity in the rumen. British Journal of Nutrition, v.64, p.285-299, 1990. DOI: $10.1079 /$ BJN19900029.

CASALI, A.O.; DETMANN, E.; VALADARES FILHO, S. de C.; PEREIRA, J.C.; HENRIQUES, L.T.; FREITAS, S.G. de; PAULINO, M.F. Influência do tempo de incubação e do tamanho de partículas sobre os teores de compostos indigestíveis em alimentos e fezes bovinas obtidos por procedimentos in situ. Revista Brasileira de Zootecnia, v.37, p.335-342, 2008. DOI: 10.1590/S1516-35982008000200021.

CHEN, X.B.; GOMES, M.J. Estimation of microbial protein supply to sheep and cattle based on urinary excretion of purine derivatives - an overview of technical details. Aberdeen: International Feed Research Unit, Rowett Research Institute, 1992. $21 \mathrm{p}$.

CHUNG, Y.H.; RICO, E.D.; MARTINES, M.C.; CASSIDY, T.W.; NOIROT, V.; AMES, A.; VARGA, G.A. Effects of feeding dry glycerin to early postpartum Holstein dairy cows on lactational 
performance and metabolic profiles. Journal of Dairy Science, v.90, p.5682-5691, 2007. DOI: 10.3168/jds.2007-0426.

DETMANN, E.; PAULINO, M.F.; MANTOVANI, H.C.; VALADARES FILHO, S. de C.; SAMPAIO, C.B.; SOUZA, M.A. de; LAZZARINI, Í.; DETMANN, K.S.C. Parameterization of ruminal fibre degradation in low-quality tropical forage using Michaelis-Menten kinetics. Livestock Science, v.126, p.136-146, 2009. DOI: 10.1016/j.livsci.2009.06.013.

ELAM, N.A.; ENG, K.S.; BECHTEL, B.; HARRIS, J.M.; CROCKER, R. Glycerol from biodiesel production: considerations for feedlot diets. In: ANNUAL SOUTHWEST NUTRITION AND MANAGEMENTCONFERENCE,23.,2008, Tucson.Proceedings. Tucson: University of Arizona, 2008. Available at: <http:// ag.arizona.edu/ANS/swnmc/Proceedings/2008/05Elam_08.pdf $>$. Accessed on: 29 jan. 2015.

FARIAS, M. de S.; PRADO, I.N.; VALERO, M.V.; ZAWADZKI, F.; SILVA, R.R.; EIRAS, C.E.; RIVAROLI, D.C.; LIMA, B.S. Níveis de glicerina para novilhas suplementadas em pastagens: desempenho, ingestão, eficiência alimentar e digestibilidade. Semina: Ciências Agrárias, v.33, p.1177-1188, 2012.

FUJIHARA, T.; ØRSKOV, E.R.; REEDS, P.J.; KYLE D.J. The effect of protein infusion on urinary excretion of purine derivatives in ruminants nourished by intragastric nutrition. The Journal of Agricultural Science, v.109, p.7-12, 1987. DOI: 10.1017/ S0021859600080916.

HALL, M.B. Neutral detergent-soluble carbohydrates nutritional relevance and analysis: a laboratory manual. Gainesville: Institute of Food and Agricultural Sciences, University of Florida, 2000. 42p. (Bulletin, 339).

HORWITZ, W.; LATIMER JUNIOR, G.W. (Ed.). Official methods of analysis of the association analytical chemists. $18^{\text {th }}$ ed. Maryland: AOAC International, 2005.

LEÃO, J.P.; RAMOS, A.T.; MARUO, V.M.; SOUZA, D.P.M. de; NEIVA, J.N.M.; RESTLE, J.; MORON, S.E. Anatomopatologia de amostras de bovinos alimentados com glicerol. Ciência Rural, v.42, p.1253-1256, 2012. DOI: 10.1590/ S0103-84782012005000046.

MERTENS, D.R. Gravimetric determination of amylase-treated neutral detergent fiber in feeds with refluxing in beakers or crucibles: collaborative study. Journal of AOAC International, v.85, p.1217-1240, 2002.

NATIONAL RESEARCH COUNCIL. Nutrient requirements of beef cattle. $7^{\text {th }}$ ed. Washington: National Academic, 2000. 242p.

PAGGI, R.A.; FAY, J.P.; FAVERIN, C. In vitro ruminal digestibility of oat hay and cellulolytic activity in the presence of increasing concentrations of short-chain acids and glycerol. Journal of Agricultural Science, v.142, p.89-96, 2004. DOI: 10.1017/ S0021859604003958.

PARSONS, G.L.; SHELOR, M.K.; DROUILLARD, J.S. Performance and carcass traits of finishing heifers fed crude glycerin. Journal of Animal Science, v.87, p.653-657, 2009.

PAULINO, M.F.; DETMANN, E.; VALENTE, E.E.L.; BARROS, L.V. de. Nutrição de bovinos em pastejo. In: SIMPÓSIO SOBRE MANEJO ESTRATÉGICO DA PASTAGEM, 4., 2008, Viçosa. Anais. Viçosa: DZO-UFV, 2008. p.131-169.

PERIPOLLI, V.; PRATES, Ê.R.; BARCELLOS, J.O.J.; WILBERT, C.A.; CAMARGO, C.M.; LOPES, R.B.; COSTA JUNIOR, J.B.G. Effect of crude glycerol on in-vitro ruminal fermentation kinetics. Revista Brasileira de Saúde e Produção Animal, v.15, p.172-181, 2014. DOI: 10.1590/S1519-99402014000100015.

PYATT, A.; DOANE, P.H.; CECAVA, M.J. Effect of crude glycerin in finishing cattle diets. Journal of Animal Science, v.85, p.412, 2007. Supplement 1

SAMPAIO, C.B.; DETMANN, E.; PAULINO, M.F.; VALADARES FILHO, S.C.; SOUZA, M.A. de; LAZZARINI, I.; PAULINO, P.V.R.; QUEIROZ, A.C. de. Intake and digestibility in cattle fed low-quality tropical forage and supplemented with nitrogenous compounds. Tropical Animal Health and Production, v.42, p.1471-1479, 2010. DOI: 10.1007/s11250-010-9581-7.

VALADARES FILHO, S. de C.; MARCONDES, M.I.; CHIZZOTTI, M.L.; PAULINO, P.V.R. (Ed.). Exigências nutricionais de zebuínos puros e cruzados: BR-corte. 2.ed. Viçosa: Ed. da UFV, 2010. 185p.

VALADARES FILHO, S. de C.; PINA, D. dos S. Fermentação ruminal. In: BERCHIELLE, T.T.; PIRES, A.V.; OLIVEIRA, S.G. de. Nutrição de ruminantes. Jaboticabal: Funep, 2006. 583p.

VAN SOEST, P.J.; ROBERTSON, J.B. Analysis of forages and fibrous foods. Ithaca: Cornell University, 1985. 202p.

$\overline{\text { Recebido em } 20 \text { de junho de } 2014 \text { e aprovado em } 3 \text { de fevereiro de } 2015}$ 